\title{
Effectiveness of Team Quiz Method in Improving The Tajweed Learning and Student Activity at SDLB Putramanunggal Gombong
}

\author{
Budiono \\ SLB ABC Putramanunggal Gombong \\ budionoputracilacap@gmail.com
}

\section{Article History}

accepted 24/09/2019

approved 01/10/2019

published 01/12/2019

\begin{abstract}
This study aims to determine the effectiveness of team quiz method to improve the tajweed learning and student activity on students with visual impairments in grade 4 at SDLB Putra Manunggal Gombong, Kebumen. This research is a classroom action research with 6 students as the research subjects. This study consisted of 2 cycles that each cycle has 2 times of meetings. The utilized instruments were test sheet, interview sheet, and observation sheet. Triangulation techniques was used to validate the data. The results showed that: 1) the team quiz method was effective in improving the tajweed learning and student activity that achieved a good category; 2) the tajweed learning was increased an average value in the first cycle by number 57,5 with $58,33 \%$ learning completeness whereas in the second cycle was 75 with $91,66 \%$ learning completeness; 3 ) the student activity was increased with an average score in the first cycle was 27 and in the second cycle was 35.
\end{abstract}

Keywords: effectiveness, team quiz method, tajweed learning, student activity

\section{Abstrak}

Penelitian ini bertujuan untuk menngetahui efektivitas metode tim quiz dalam meningkatkan pembelajaran ilmu tajwid dan keaktifan peserta didik tunanetra kelas 4 di SDLB Putra Manunggal Gombong, Kebumen. Penelitian ini merupakan penelitian tindakan kelas dengan subyek penelitian berjumlah 6 peserta didik. Penelitian ini menggunakan dua siklus dengan masing-masing siklus terdiri dari 2 kali pertemuan. Instrumen dalam penelitian ini berupa lembar tes, lembar interview, dan lembar observasi. Teknik validitas data menggunakan teknik triangulasi. Hasil penelitian menunjukkan bahwa: 1) metode tim quiz efektif digunakan untuk meningkatkan pembelajaran ilmu tajwid dan keaktifan peserta didik dengan kategori baik; 2) Pemahaman ilmu tajwid peserta didik mengalami peningkatan dengan nilai rata-rata pada siklus pertama sebesar 57,5 dengan jumlah ketuntasan $58,33 \%$ dan pada siklus kedua sebesar 75 dengan jumlah ketuntasan $91,66 \%$; 3) keaktifan peserta didik mengalami peningkatan dengan rata-rata jumlah skor pada siklus pertama sebanyak 27 dan pada siklus kedua sebanyak 35 .

Kata kunci: efektivitas, metode tim quiz, pembelajaran tajwid, keaktifan siswa

Social, Humanities, and Education Studies (SHEs): Conference Series https://jurnal.uns.ac.id/shes

p-ISSN 2620-9284

e-ISSN 2620-9292 


\section{PENDAHULUAN}

Menurut Undang-undang Sisdiknas disebutkan bahwa pendidikan adalah usaha sadar dan terencana untuk mewujudkan suasana belajar dan proses pembelajaran agar peserta didik secara aktif mengembangkan potensi dirinya untuk memiliki kekuatan spiritual keagamaan, pengendalian diri, kepribadian, kecerdasan, akhlak mulia, serta keterampilan yang diperlukan dirinya, masyarakat, bangsa dan negara (Pasal 1 ayat 1 UU RI Nomor 20 tahun 2003). Dalam upaya mewujudkan pembelajaran yang aktif dan menyenangkan, seorang pendidik harus memiliki kreativitas dan inovatif. Pembelajaran yang bervariasi akan memberikan kesan bahwa materi yang disampaikan akan selalu menyenangkan dan tidak monoton. Sehingga siswa akan lebih semangat dan tertarik dalam menerima materi. Pembelajaran agama islam (PAI) merupakan salah satu mata pelajaran yang wajib bagi siswa sekolah dasar. Salah satu materi yang disampaikan di kelas 4 adalah membaca surah pendek dengan makhraj yang benar dan tepat. Membaca surah pendek dengan makhraj yang benar dan tepat diperlukan pemahaman tentang ilmu tajwid. Alam (2006) menjelaskan bahwa ilmu tajiwd adalah suatu ilmu pengetahuan cara membaca AI-Qur'an dengan baik dan tertib menurut makhrajnya, panjang pendeknya, tebal tipisnya, berdengung atau tidaknya, irama dan nadanya, serta titik komanya yang sudah diajarkan oleh Rasulullah kepada para sahabatnya. Mempelajari ilmu tajwid merupakan suatu kewajiban yang bertujuan untuk memberikan tuntunan bagaimana cara pengucapan ayat yang tepat, sehingga lafal dan maknanya terpelihara. Pengetahuan tentang makharij al-huruf memberikan tuntunan bagaimana cara mengeluarkan huruf dari mulut dengan benar. Pengetahuan tentang sifat huruf berguna dalam pengucapan huruf (Yullah, 2015).

Berdasarkan hasil observasi di SDLB Putramanunggal Gombong khususnya siswa tunanetra kelas 4 , pembelajaran agama islam khususnya materi tajwid masih sering disampaikan dengan menggunakan metode ceramah. Pada dasarnya ada beberapa siswa yang mampu menghafal surah-surah pendek, namun kurang adanya perhatian pada makhrajnya sehingga siswa hanya sebatas menghafal bagimana kalimatnya bukan bagaimana menghafal dan membaca Al-quran dengan makhraj yang benar dan tepat. Siswa lebih banyak mendengarkan materi dari guru dan jarang sekali dilakukan pembelajaran yang memberikan kesempatan kepada siswa untuk berdiskusi dan bertanya. Hal ini berdampak pada kurangnya keterampilan siswa dalam berpikir dan pasif selama pembelajaran. Aktivitas siswa sangat kurang sehingga pembelajaran terasa membosankan. Oleh sebab itu, diperlukan kreativitas dalam pembelajaran khususnya pembelajaran agama. Salah satu metode yang dapat digunakan untuk pembelajaran agama adalah metode pembelajaran aktif tipe team quiz. Pembelajaran aktif adalah suatu proses dimana siswa secara aktif terlibat membangun pemahaman fakta, gagasan, dan keterampilan melalui penyelesaian instruktur diarahkan tugas dan kegiatan. Ini adalah jenis kegiatan yang membuat siswa terlibat dalam proses pembelajaran (Kusumawati, 2017). Raisal \& Suwondo (2018) menjelaskan bahwa pembelajaran aktif adalah pembelajaran yang mengajak siswa untuk belajar secara aktif. Ketika siswa belajar secara aktif, maka siswa lebih banyak mendominasi selama pembelajaran dan kemampuan berpikir anak juga akan semakin terasah.

Silberman (2006) menyebutkan bahwa quiz team merupakan teknik pembelajaran aktif yang mana dalam teknik ini siswa dibagi menjadi tiga tim. Setiap siswa dalam tim bertanggung jawab untuk menyiapkan kuis jawaban singkat, dan tim yang lain menggunakan waktunya untuk memeriksa catatan. Wibisono (2015) menyebutkan bahwa dengan menggunakan pembelajaran aktif tipe team quiz, suasana kelas akan menjadi menyenangkan dan siswa akan tertarik untuk aktif dalam pembelajaran.

Berdasarkan latar belakang di atas, metode team quiz diharapkan dapat meningkatkan pembelajaran ilmu tajwid dan keaktifan peserta didik tunanetra kelas 4 di SDLB Putra Manunggal Gombong, Kebumen. 


\section{METODE}

Penelitian ini merupakan penelitian tindakan kelas (PTK) yang dilaksanakan dalam 2 siklus yang masing-masing terdiri dari 2 pertemuan. Setiap siklus terdiri dari tahap perencanaan, pelaksanaan, observasi, dan refleksi. Subjek penelitian adalah siswa kelas 4 di SDLB Putra Manunggal Gombong, Kebumen yang berjumlah 6 siswa. Teknik pengumpulan data melalui observasi, interview, dan tes. Validitas data menggunakan teknik triangulasi. Gambar 1 adalah desain penelitian tindakan kelas pada penelitian ini.

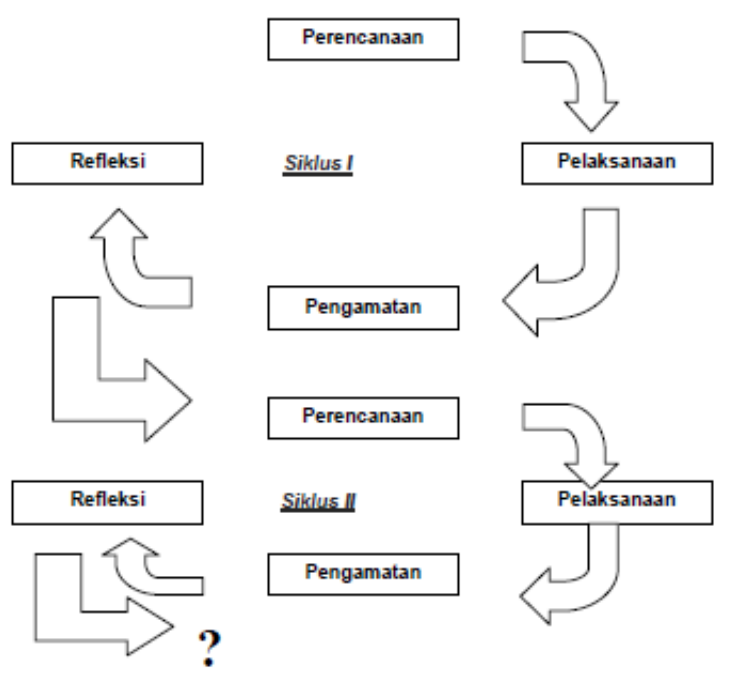

\section{Gambar 1. Desain Penelitian Tindakan Kelas}

(Sumber: Arikunto, 2010)

Untuk mengetahui hasil tes pembelajaran ilmu tajwid dikategorikan pada tabel 1.

Tabel 1. Kriteria Kemampuan Membaca Tajwid

\begin{tabular}{ccc}
\hline No & Rentang Nilai & Kriteria \\
\hline 1 & $80-100$ & Sangat Baik \\
2 & $66-79$ & Baik \\
3 & $56-65$ & Cukup \\
4 & $40-55$ & Kurang \\
5 & $\leq 39$ & Gagal \\
\hline \multicolumn{2}{c}{ (Sumber Didapatasi dari: Arikunto, 2010) }
\end{tabular}

Berdasarkan pengolahan data keefektifan selanjutnya diinterpretasikan tingkat keefektifannya. Metode tim kuis dikatakan efektif jika rata-rata nilai hasil pembelajaran tajwid peserta didik mencapai $\geq 70$. Jika kurang dari 70 , maka dikatakan tidak efektif. Artinya, jika rata-rata nilai hasil pembelajaran tajwid peserta didik mencapai $\geq 70$, metode tim kuis yang digunakan dapat dikatakan memiliki peran yang efektif dalam meningkatkan pembelajaran ilmu tajwid. Kriteria keefektifan yang digunakan sebagai pedoman dapat dilihat pada tabel 2.

Tabel 2. Kriteria Keefektifan Pembelajaran

\begin{tabular}{cc}
\hline Skor Keefektifan & Kriteria \\
\hline $85-100$ & Sangat efektif \\
$70-84$ & Efektif \\
$50-69$ & Kurang efektif \\
$0-49$ & Tidak efektif \\
\hline
\end{tabular}

(Sumber Didapatasi dari: Arikunto, 2010) 
Sedangkan untuk mengetahui kriteria keaktifan siswa dapat dilihat pada tabel 3. Metode tim kuis dikatakan efektif jika rata-rata skor keaktifan peserta didik mencapai $\geq$ 25. Jika kurang dari 25, maka dikatakan tidak efektif. Artinya, jika rata-rata skor keaktifan peserta didik mencapai $\geq 25$, metode tim kuis yang digunakan dapat dikatakan memiliki peran yang efektif dalam meningkatkan keaktifan siswa.

Tabel 3. Kriteria Skor Keaktifan Siswa

\begin{tabular}{cccc}
\hline No & Rerata Skor & Kriteria & Keterangan \\
\hline 1 & $35-45$ & Sangat Baik & Sangat Efektif \\
2 & $25-34$ & Baik & Efektif \\
4 & $15-24$ & Kurang Baik & Tidak Efektif \\
\hline \multicolumn{4}{c}{ (Sumber: Diadaptasi dari Widoyoko: 2012) }
\end{tabular}

HASIL DAN PEMBAHASAN

Sebelum pembelajaran menggunakan metode tim kuis, guru melakukan pra tindakan untuk mengetahui kemampuan awal pembelajaran ilmu tajwid pada siswa yang dapat dilihat pada tabel 4.

Tabel 4. Hasil Kemampuan Awal Pembelajaran IImu tajwid

\begin{tabular}{ccc}
\hline Siswa ke- & Nilai Kemampuan Awal & Kriteria \\
\hline 1 & 20 & Gagal \\
2 & 42 & Kurang \\
3 & 10 & Gagal \\
4 & 40 & Kurang \\
5 & 35 & Gagal \\
6 & 15 & Gagal \\
\hline Rata-Rata & $\mathbf{2 7}$ & Gagal
\end{tabular}

Berdasarkan hasil nilai kemampuan awal seperti pada tabel 4, seluruh siswa belum mampu memahami ilmu tajwid dengan lancar dan benar. Berdasarkan hasil observasi awal, keaktifan siswa dalam pembelajaran belum terlihat secara maksimal. Satu dari enam siswa $(16,67 \%)$ telah memiliki keaktifan yang cukup baik di dalam pembelajaran. Mengacu pada hasil kemampuan awal dan observasi tersebut, diperlukan tindakan lanjutan untuk meningkatkan pembelajaran ilmu tajwid dan keaktifan siswa yaitu dengan menggunakan metode tim kuis. Metode ini dilakukan dengan langkah-langkah sebagai berikut (Suprijono, 2009: 114):

1. Memilih topik pembelajaran yang dapat disampaikan dalam tiga bagian;

2. Siswa dibagi menjadi 3 kelompok, yaitu kelompok $A$, kelompok $B$, dan kelompok C;

3. Guru menyampaikan skenario pembelajaran metode tim kuis, kemudian dilanjutkan dengan penyampaian materi;

4. Setelah penyampaian materi selesai, lalu minta kelompok A menyiapkan pertanyaan-pertanyaan yang berkaitan dengan materi yang telah disampaikan tadi;

5. Kemudian guru meminta kelompok $A$ memberikan pertanyaan tersebut kepada kelompok B. Apabila kelompok B tidak dapat menjawab pertanyaan dari kelompok A, maka pertanyaan teresebut dilemparkan kepada kelompok C;

6. Selanjutnya kelompok A memberikan pertanyaan kepada kelompok C. Apabila kelompok $C$ tidak dapat menjawab pertanyaan dari kelompok $A$, maka pertanyaan dilemparkan kepada kelompok B. Jika tanya jawab selesai maka dilanjutkan ka materi kedua. Tunjuk kelompok B sebagai kelompok penanya. Proses tanya jawab pada sesi kedua ini sama dengan ketika kelompok A menjadi kelompok penanya; 
7. Setelah kelompok B selesai dengan pertanyaan yang diajukan, maka dilanjutkan dengan penyampaian materi ketiga. Tunjuk kelompok $\mathrm{C}$ sebagai kelompok penanya;

8. Ketika tanya jawab kelompok $A$, kelompok B dan kelompok $C$ selesai, maka pembelajaran diakhiri dengan menyimpulkan dari hasil tanya jawab. Berikan penjelasan jika ada yang kurang paham atau jika ada pertanyaan atau jawaban yang keliru.

Pertemuan pertama di siklus I guru membentuk siswa menjadi 3 tim yang berbeda, yaitu tim A, tim B, dan tim C. Tim tersebut juga berlaku untuk pertemuan selanjutnya. Guru menyampaikan materi tentang surah pendek al-kautsar. Guru membaca ayat tiap ayat surah al-kautsar dengan makhraj yang benar kemudian siswa mengikuti. Guru mengulangi membaca surah al-kautsar yang diikuti oleh siswa sebanyak tiga kali. Setelah dirasa cukup, guru bertanya kepada siswa "siapa yang sudah dapat membaca surah al-kautsar?'. Guru mengecek bacaan siswa satu per satu dan tetap membimbing siswa yang belum bisa melafalkannya. Setelah guru selesai membimbing siswa untuk membaca surah al-kautsar, guru memberikan pengenalan hukum-hukum tajwid yang kemudian diaplikasikan di surah al-kaustar. Pada pertemuan $1 \mathrm{di}$ siklus I ini belum semua siswa bisa melafalkan surah al-kautsar dengan menggunakan mahraj yang benar dan tepat.

Berdasarkan hasil observasi, penyebab siswa belum bisa melafalkan surah alkautsar dengan mahraj yang benar adalah pada dasarnya beberapa siswa sudah menghafal surah al-kautsar karena sudah dibiasakan di rumah oleh orang tuanya, namun bacaan tersebut tidak memperhatikan mahrajnya sehingga ketika diajarkan tentang mahraj yang benar, siswa masih belum terbiasa. Siswa cenderung ingin cepat selesai dalam membacanya tanpa memperhatikan mahrajnya. Secara keseluruhan sebanyak 33,33\% siswa bisa membaca surah al-kautsar, namun belum bisa menyesuaikan bacaanya dengan mahraj yang benar. Oleh sebab itu, di pertemuan kedua guru memberikan latihan secara terus-menerus kepada siswa agar bisa melafalkan surah al-kautsar dengan bacaan yang benar, begitu pula bagi siswa yang belum bisa membacanya, siswa yang sudah bisa membaca dengan benar memberikan contoh kepada siswa yang belum bisa. Setelah semua siswa mampu melafalkan surah al-kaustar, guru memberikan penjelasan ulang tentang hukum-hukum tajwid di dalam surah al-kautsar.

Setelah siswa menyimak penjelasan dari guru, siswa yang sudah dibentuk tim kelompok oleh guru mulai melakukan tugasnya. Tim A membuat pertanyaan tentang surah al-kaustar yang telah disampaikan. Selanjutnya, tim B membuat pertanyaan seputar mahraj dalam surah al-kaustar. Sedangkan tim C membuat pertanyaan tentang makna surah al-kaustar.

Tabel 5. Hasil Nilai Pembelajaran IImu Tajwid Siklus I

\begin{tabular}{cccc}
\hline Pertemuan ke- & Rata-Rata Nilai & Kriteria & Ketuntasan (\%) \\
\hline I & 55 & Kurang & $50,00 \%$ \\
II & 60 & Cukup & $66,66 \%$ \\
\hline Rata-Rata Total & $\mathbf{5 7 , 5}$ & Cukup & $\mathbf{5 8 , 3 3 \%}$ \\
\hline
\end{tabular}

Berdasarkan tabel 5, nilai pembelajaran ilmu tajwid di siklus I menunjukkan kriteria cukup dengan rata-rata nilai 57,5 dengan persentase ketuntasan sebesar $58,33 \%$. Hasil ini membuktikan bahwa terdapat peningkatan dari kemampuan awal siswa sebelum diberikan tindakan.

Tabel 6. Hasil Skor Keaktifan Pembelajaran IImu Tajwid Siklus I

\begin{tabular}{cccc}
\hline Pertemuan ke- & Rata-Rata Skor & Kriteria & Ketuntasan (\%) \\
\hline I & 24 & Kurang & $66,66 \%$ \\
II & 30 & Baik & $83,33 \%$ \\
\hline Rata-Rata Total & $\mathbf{2 7}$ & Baik & $\mathbf{7 4 , 9 9 \%}$ \\
\hline
\end{tabular}


Berdasarkan tabel 6, skor keaktifan siswa pada pembelajaran ilmu tajwid dengan menggunakan tim kuis menunjukkan kriteria baik dengan persentase ketuntasan sebesar $74,99 \%$. Pembelajaran ilmu tajwid dengan menggunakan tim kuis memberikan kesempatan kepada siswa untuk berkolaborasi untuk membuat jawaban yang tepat. Sehingga aktivitas siswa selama pembelajaran akan semakin berkembang. Secara keseluruhan, pada siklus I telah terjadi peningkatan. Namun, masih perlu ditingkatkan lagi agar menghasilkan yang lebih baik. Berdasarkan hasil wawancara, siswa masih bingung untuk membedakan jenis-jenis tajwid ketika sudah diaplikasikan ke dalam surah pendek. Menurut siswa bacaan ikhfa dan idhar adalah bacaan yang paling mudah di pahami, namun bacaan idghom, qoloqolah dan jenis-jenis mad merupakan bacaan yang dianggap sulit oleh siswa untuk dipahami. Kesulitan itu dirasakan oleh siswa karena jumlah mad yang banyak jenisnya dan cara membacanya juga berbedabeda. Oleh sebab itu, perlu dilanjutkan ke siklus II untuk dapat meningkatkan hasil yang diharapkan.

Pembelajaran di siklus II guru mengulang jenis-jenis bacaan tajwid yang dirasa sulit dipahami oleh siswa yaitu memfokuskan pada bacaan idghom, qoloqolah dan mad. Guru memberikan contoh beberapa bacaan idghom, qolqolah dan bacaanbacaan mad dengan memberikan tanya jawab seputar bacaan idghom dan mad. Melalui tanya jawab ini guru sekalian mengecek pemahaman siswa. Selanjutnya guru memberikan latihan soal kepada siswa dan dikerjakan secara berkelompok dengan tim yang telah dibuat. Melalui diskusi dan kerjasama, siswa dapat memberikan ide/gagasan yang lebih banyak sehingga mampu membangun pemahaman siswa. Putriyanti \& Fensi (2017) menyebutkan bahwa melalui diskusi kelompok, siswa akan aktif berpikir dan melatih mengemukakan pendapat sehingga suasana kelas menjadi lebih hidup. Setelah dilakukan diskusi, guru mengarahkan masing-masing tim untuk membuat pertanyaan-pertanyaan untuk kuis. Tim A membuat pertanyaan seputar bacaan idghom, kelompok B membuat pertanyaan tentang beberapa jenis mad (mad thabi'i, mad wajib muttasil, mad jaiz munfashil, mad layyin, dan lain-lain), dan tim $\mathrm{C}$ membuat pertanyaan tentang bacaan qolqolah.

Tabel 7. Hasil Nilai Pembelajaran IImu Tajwid Siklus II

\begin{tabular}{cccc}
\hline Pertemuan ke- & Rata-Rata Nilai & Kriteria & Ketuntasan (\%) \\
\hline I & 70 & Baik & $83,34 \%$ \\
II & 80 & Sangat Baik & $100 \%$ \\
\hline Rata-Rata Total & 75 & Baik & $\mathbf{9 1 , 6 6 \%}$ \\
\hline
\end{tabular}

Berdasarkan tabel 7, nilai pemahaman siswa pada pembelajaran ilmu tajwid dengan menggunakan tim kuis pada siklus II menunjukkan kriteria baik dengan persentase ketuntasan sebesar 91,66\%. Namun, jika dilihat pada pertemuan kedua, semua siswa mampu memahami bacaan tajwid dengan baik yaitu mencapai $100 \%$. Mengacu pada hasil tersebut dapat dikatakan bahwa metode tim kuis efektif dalam meningkatkan pembelajaran ilmu tajwid di sekolah dasar kelas 4.

Tabel 8. Hasil Skor Keaktifan Pembelajaran IImu Tajwid Siklus II

\begin{tabular}{cccc}
\hline Pertemuan ke- & Rata-Rata Skor & Kriteria & Ketuntasan (\%) \\
\hline I & 34 & Baik & $100 \%$ \\
II & 36 & Sangat Baik & $100 \%$ \\
\hline Rata-Rata Total & $\mathbf{3 5}$ & Sangat Baik & $\mathbf{1 0 0 \%}$ \\
\hline Berdasarkan tabel & $\mathbf{8}$, skor & kekatifan & siswa pada pembelajaran ilmu tajwid
\end{tabular}
dengan menggunakan tim kuis pada siklus II menunjukkan kriteria sangat baik dengan persentase ketuntasan sebesar $100 \%$. Mengacu pada hasil tersebut dapat dikatakan bahwa metode tim kuis efektif dalam meningkatkan keaktifan siswa di sekolah dasar kelas 4 pada pembelajaran ilmu tajwid. Hal ini sejalan dengan penelitian Wibisino (2015) yang menjelaskan bahwa metode team quiz dapat meningkatkan keaktifan 
siswa selama pembelajaran. Dilanjutkan dalam penelitian Raisal, dkk (2018) menjelaskan bahwa metode tim kuiz efektif digunakan untuk meningkatkan keaktifan siswa. Metode tim kuis merupakan metode yang mengutamakan kekompakkan dan kerjasama dari sebuah tim untuk menemukan jawaba/solusi yang terbaik. Melalui metode ini, siswa akan lebih antusias dan tertantang dalam pembelajaran dikarenakan untuk menemukan sebuah solusi dan jawaban dibatasi oleh waktu. Kusumawati (2017) menyebutkan bahwa dengan adanya sistem pertandingan akademis ini akan tercipta kompetisi antar kelompok sehingga siswa akan senantiasa berusaha belajar dengan semangat yang tinggi agar dapat memperoleh nilai yang tinggi. Kemudian diakhir pembelajaran, tim yang mendapatkan nilai paling banyak diberikan penghargaan oleh guru, sedangkan tim yang mendapatkan nilai rendah selalui dimotivasi oleh guru untuk lebih giat berlatih dan membaca.

\section{SIMPULAN}

Hasil penelitian menunjukkan bahwa: 1) metode tim quiz efektif digunakan untuk meningkatkan pembelajaran ilmu tajwid dan keaktifan peserta didik dengan kategori baik; 2) Pemahaman ilmu tajwid peserta didik mengalami peningkatan dengan nilai rata-rata pada siklus pertama sebesar 57,5 dengan jumlah ketuntasan $58,33 \%$ dan pada siklus kedua sebesar 75 dengan jumlah ketuntasan 91,66\%; 3) keaktifan peserta didik mengalami peningkatan dengan rata-rata jumlah skor pada siklus pertama sebanyak 27 dan pada siklus kedua sebanyak 35.

\section{DAFTAR PUSTAKA}

Alam, D. T. (2006). IImu Tajwid Populer 17 Kali Pandai. Yogyakarta: Bumi Aksara.

Arikunto, S. (2010). Prosedur Penelitian Suatu Pendekatan Praktek. Jakarta: Rineka Cipta.

Kusumawati, N. (2017). Penerapan Metode Active Learning Tipe Team Quiz untuk Meningkatkan Keaktifan Bertanya dan Kreativitas Siswa pada Mata Pelajaran IPA Kelas V SDN Ronowijan Ponorogo. Jurnal Bidang Pendidikan Dasar, Vol 1 (2), 2636.

Putriyanti, C.C., \& Fensi, F. (2017). Penerapan Metode Diskusi Kelompok untuk Meningkatkan Hasil Belajar Siswa pada Mata Pelajaran IPS di Kelas IX SMP Santa Maria Monica, Bekasi Timur. Jurnal Psibernetika, Vol 10 (2), 114-122.

Raisal, A., Y., \& Suwondo, N. (2018). Effectiveness of Active Learning Method Quiz Team Type on Student Learning Outcomes in Subject Ohm Law in SMA Negeri 1 Pundong. Indonesian Review of Physics, Vol 1 (2), 33-36.

Silberman, M.L. (2006). Acitve Learning 101 Cara Belajar Siswa Aktif. Bandung: Nuansa.

Suprijono, A. (2009). Cooperative Learning: Teori dan Aplikasi PAIKEM. Yogyakarta: Pustaka Pelajar.

Wibisono, W. (2015). Penerapan Model Pembelajaran Kooperatif Tipe Team Quiz dalam Meningkatkan Keaktifan Belajar Siswa. Prosiding Seminar Nasional PAP "Pengembangan Ilmu dan Profesi Administrasi Perkantoran: Peluang dan Tantangan", 169-179.

Widoyoko, E., P. (2012). Teknik Penyusunan Instrumen Penelitian. Yogyakarta: Pustaka Pelajar.

Yullah, R. (2015). Metode Pembelajaran Tajwid Didayah Jabal Nur Kecamatan Dewantara Kabupaten Aceh Utara. Jurnal IImiah Didakta, Vol 15 (2), 244-265. 